\title{
Low-frequency acoustic-gravity
} waves from coseismic vertical deformation associated with the 2004 Sumatra-Andaman earthquake $(\mathrm{Mw}=9.2)$

\section{$\operatorname{AUTHOR}(\mathrm{S}):$}

Mikumo, Takeshi; Shibutani, Takuo; Le Pichon, Alexis; Garces, Milto; Fee, David; Tsuyuki, Takahiro; Watada, Shingo; Morii, Wataru

\section{CITATION:}

Mikumo, Takeshi ...[et al]. Low-frequency acoustic-gravity waves from coseismic vertical deformation associated with the 2004 Sumatra-Andaman earthquake (Mw=9.2). Journal of Geophysical Research: Solid Earth 2008, 113(B12): B12042.

\section{ISSUE DATE:}

2008-12-05

URL:

http://hdl.handle.net/2433/193422

RIGHT:

Copyright 2008 by the American Geophysical Union. 


\title{
Low-frequency acoustic-gravity waves from coseismic vertical deformation associated with the 2004 Sumatra-Andaman earthquake $\left(M_{w}=9.2\right)$
}

\author{
Takeshi Mikumo, ${ }^{1,2,3}$ Takuo Shibutani, ${ }^{2}$ Alexis Le Pichon, ${ }^{4}$ Milton Garces, ${ }^{5}$ David Fee, ${ }^{5}$ \\ Takahiro Tsuyuki, ${ }^{6}$ Shingo Watada, ${ }^{7}$ and Wataru Morii ${ }^{2}$ \\ Received 15 March 2008; revised 7 July 2008; accepted 9 September 2008; published 5 December 2008.
}

[1] Atmospheric pressure perturbations from the 2004 Sumatra-Andaman earthquake $\left(M_{w}=9.2\right)$ were observed by sensitive microbarographs at several global stations. Among these observations, very low-frequency acoustic-gravity waves $(\sim 1.4-2.8 \mathrm{mHz})$ with a group velocity around $300-314 \mathrm{~m} / \mathrm{s}$ and amplitudes ranging between $\sim 1$ and $12 \mathrm{~Pa}$ can be clearly identified through data processing at four stations on the Japanese Islands and also at four International Monitoring System (IMS) stations around the Indian Ocean. Assuming several seismic source parameters for this great thrust earthquake, we produce synthetic barograms using a realistic thermal structure in the atmosphere up to an altitude of $220 \mathrm{~km}$. For this modeling, we incorporate the source dimensions in different zones, the expanding velocity of the source region, the vertical displacements of uplift and subsidence, and their time constants. Combinations of these source parameters provide synthetic waveforms consistent with the general features of the observed low-frequency records. The results clearly indicate that the recorded waves may have been generated by large-scale coseismic uplift and subsidence of the sea bottom and associated swelling and depression of the sea surface over the source region extending for $1500 \mathrm{~km}$. The uplift in the south-central zone of the Andaman-Nicobar regions may be substantially larger than in the other zones. The time constant of the coseimic vertical deformation is found to be in the range of $1.0-1.5 \mathrm{~min}$, which may correspond to the time elapsed shortly before the generation of tsunami waves.

Citation: $\quad$ Mikumo, T., T. Shibutani, A. Le Pichon, M. Garces, D. Fee, T. Tsuyuki, S. Watada, and W. Morii (2008), Low-frequency acoustic-gravity waves from coseismic vertical deformation associated with the 2004 Sumatra-Andaman earthquake $\left(M_{w}=9.2\right)$, J. Geophys. Res., 113, B12402, doi:10.1029/2008JB005710.

\section{Introduction}

[2] The great Sumatra-Andaman earthquake $\left(M_{w}=9.2\right)$ that took place on 26 December 2004 in the Indian Ocean $\left(3.31^{\circ} \mathrm{N}, 95.95^{\circ} \mathrm{E}\right.$ at $\left.0058: 53 \mathrm{UTC}\right)$ (U.S. Geological Survey (USGS) initial estimates) radiated very long-period seismic waves and also caused unusually large coseismic crustal deformations and tsunami around the source region extending for longer than $1500 \mathrm{~km}$. At the same time, infrasound waves produced by the epicentral displacement, seismic waves, and the tsunami have been observed [Garces et al., 2005; Le Pichon et al., 2005]. Ionospheric perturbations

\footnotetext{
${ }^{1}$ Instituto de Geofisica, Universidad Nacional Autonoma de Mexico, Coyoacan, Mexico. Japan.

${ }^{2}$ Disaster Prevention Research Institute, Kyoto University, Kyoto,

${ }^{3}$ Retired

${ }^{4}$ DSO, LDG, DASE, CEA, Bruyeres-le Chatel, France.

${ }^{5}$ Infrasound Laboratory, University of Hawaii, Kailua-Kona, Hawaii, USA.

${ }^{6}$ Matsushiro Seismological Observatory, JMA, Matsushiro, Japan.

${ }^{7}$ Earthquake Research Institute, University of Tokyo, Tokyo, Japan.

Copyright 2008 by the American Geophysical Union. 0148-0227/08/2008JB005710\$09.00
}

have also been detected from variations of total electron content (TEC) using GPS observations [Heki et al., 2006; Otsuka et al., 2006; DasGupta et al., 2006], from geomagnetic pulsations [Iyemori et al., 2005] and also from Doppler sounding [Liu et al., 2006]. In particular, Heki et al. [2006] related the ionospheric perturbations to direct acoustic-gravity waves emitted from the source region and successfully recovered an aspect of the earthquake rupture process. However, direct evidence for propagating acousticgravity waves generated by coseismic deformation in the source region has not yet been confirmed.

[3] In the present paper, we explore the evidence for lowfrequency acoustic-gravity waves propagating from the source through the lower atmosphere, by looking for barograph data obtained at global stations and analyzing them in detail to compare with possible theoretical predictions. Another main purpose is to reveal the source characteristics of this great earthquake, which still have not been well resolved from seismic, geodetic or tsunami data. One of the controversial problems is that seismic data suggest large fault slip mainly in the southern to central fault segments [e.g., Lay et al., 2005] and partly to the northern region, while the main fault slip appears to extend also to 


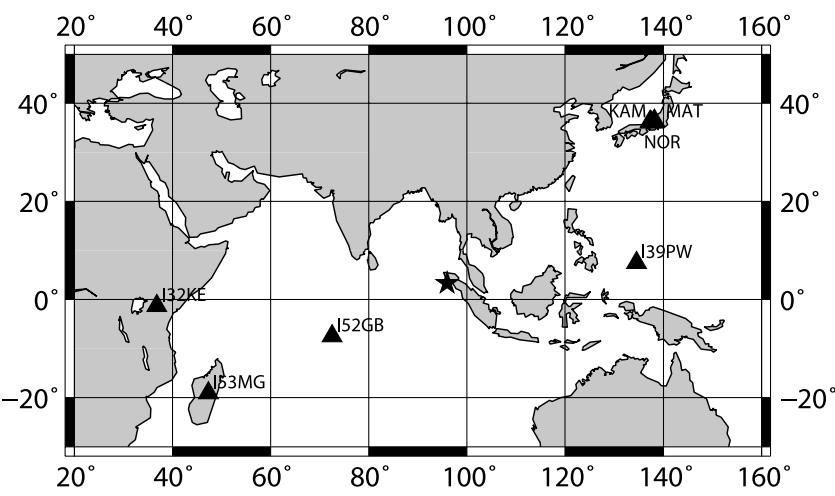

Figure 1. Location of the barograph stations that recorded acoustic-gravity waves from the 2004 Sumatra-Andaman earthquake. The star indicates the USGS epicenter.

the northern segments from the viewpoint of geodetic data [e.g., Banerjee et al., 2005, 2007]. Another problem is that some of tsunami data based on radar altimeter [Lay et al., 2005] suggest slow slip in the northern segments while the others from tide gauge records do not [Fujii and Satake, 2007]. We expect that our data from acoustic-gravity waves might be able to provide independent solutions to these unsolved and controversial problems related to the source parameters of this earthquake.

\section{Observations}

[4] Low-frequency atmospheric pressure waves have been recorded at several global microbarograph stations, including four Japanese and four International Monitoring System (IMS) stations within several hours after the 2004 great earthquake. Station locations are shown in Figure 1, which are located in the distance range between $2860 \mathrm{~km}$ and $6590 \mathrm{~km}$ from the USGS epicenter. During this time, quite large daily atmospheric disturbances were prevailing over a wide area, and hence it was necessary to extract the pressure waves from the original data through data processing in the time domain. The waveforms thus obtained are shown below.

\subsection{Japanese Stations}

[5] The pressure waves can be identified at four stations in central Japan. The microbarographs used there have a flat frequency response from $0.5 \mathrm{~Hz}$ to $\mathrm{DC}$, and the rate of data sampling is $1 \mathrm{~Hz}$. Figure 2a shows a part of two-channel records over $2400 \mathrm{~s}$ (40 $\mathrm{min})$ obtained at the Matsushiro Seismological Observatory (MAT), Japan Meteorological Agency (JMA). The two microbarographs are installed about $150 \mathrm{~m}$ apart in a deep vault (not intercepted from outside air) of the observatory. The original data have been detrended here to remove daily atmospheric variations with a maximum of $40 \mathrm{~Pa}$. It can be seen that there is a very good consistency between the two channels. The amplitude of first large compression waves reaches $\sim 9 \mathrm{~Pa}$ with a period longer than $700 \mathrm{~s}(\sim 12 \mathrm{~min})$, and the group velocity of the first peak arriving at 0556 is about $310 \mathrm{~m} / \mathrm{s}$. We notice that these characteristic features are very similar to those which have been recorded at Berkeley and other California stations after the 1964 great Alaskan earthquake $(M w=9.0)$ [Bolt, 1964; Mikumo, 1968]. Figure 2b (NOR) shows two records obtained at the Norikura National Astronomical Observatory (NAO) and the Institute for Cosmic Ray Research (ICRR), University of Tokyo, both of which are located at high altitudes around $2800 \mathrm{~m}$ and about $200 \mathrm{~m}$ apart. The original data also include large daily variations up to $50 \mathrm{~Pa}$ and hence have been detrended. We see that the first longperiod waveforms are quite similar to the records at Matsushiro, but somewhat more disturbed. The first peak arriving at 0555 has a group velocity of about $309 \mathrm{~m} / \mathrm{sec}$ with the amplitude of about $\sim 12-15 \mathrm{~Pa}$ and a period of about $700 \mathrm{~s}(\sim 12 \mathrm{~min})$. The fourth one shown in Figure 2c gives one-channel record obtained at Kamioka station (KAM), DPRI, Kyoto University. Although the original data have been detrended here, we still see much longerand shorter-period disturbances. Nevertheless, we find quite similar waveforms to the other three stations around the first $1 / 3$ central portion of the record. The amplitude is $\sim 7 \mathrm{~Pa}$ for a period of about $700 \mathrm{~s}(\sim 12 \mathrm{~min})$, and the group velocity of the first peak arriving at 0553 is about $311 \mathrm{~m} / \mathrm{s}$. Because of the waveform similarity and the group velocities estimated above, we are now inclined to believe that these waves recorded at the four stations are low-frequency acousticgravity waves propagating directly from the source region through the lower atmosphere.

\subsection{IMS Stations}

[6] Atmospheric pressure waves can also be identified at the following four IMS stations: Diego Garcia (I52GB), Kenya (I32KE), Madagascar (I33MG), and Palau (I39PW), which are located in or around the Indian Ocean. All these stations have sensor arrays with an aperture of about $2 \mathrm{~km}$, and a flat frequency response in the range $0.02-8 \mathrm{~Hz}$ [Garces et al., 2005], but decaying with $20 \mathrm{~dB} /$ decade toward lower frequencies. The sampling rate of the IMS infrasound data is $20 \mathrm{~Hz}$. Some part of the pressure records have been analyzed by Garces et al. [2005] and Le Pichon et al. [2005], and identified them as from seismic T-phases and early arriving infrasound waves from the source and resultant tsunami generation. We look for much lower-frequency signals, which will be comparable to the acoustic-gravity waves that have been recorded at the Japanese stations. To extract these waves, we apply a second-order Butterworth bandpass filter with a unit amplitude to all the IMS data over a frequency range between 1.19 and $8.33 \mathrm{mHz}$ (or $14 \mathrm{~min}$ to $2 \mathrm{~min}$ ). Our choice of the frequency range comes from the dynamic response of the lower atmosphere [Harkrider, 1964], as will be described later.

[7] Figures $2 \mathrm{~d}-2 \mathrm{~g}$ show the filtered records obtained at the four IMS stations, all of which cover the time interval of $2400 \mathrm{~s}$ (40 min). Figure 2d shows three-channel records obtained from Diego Garcia (I52). There is a good coherency in the first two channels with a period around $360 \mathrm{~s}$ ( $\sim 6 \mathrm{~min}$ ) during a time interval of about $800 \mathrm{~s}$, although the third one indicates a phase delay and somewhat distorted waveform possibly due to phase mismatch between sensors outside the passband. The first large peak at 0339 arrives with a group velocity of about $307 \mathrm{~m} / \mathrm{s}$ and with an amplitude of $0.8 \mathrm{~Pa}$. This corresponds to the initial part of the Group III wave train identified by Le Pichon et al. [2005]. The second one comes from Kenya (I32) as shown 

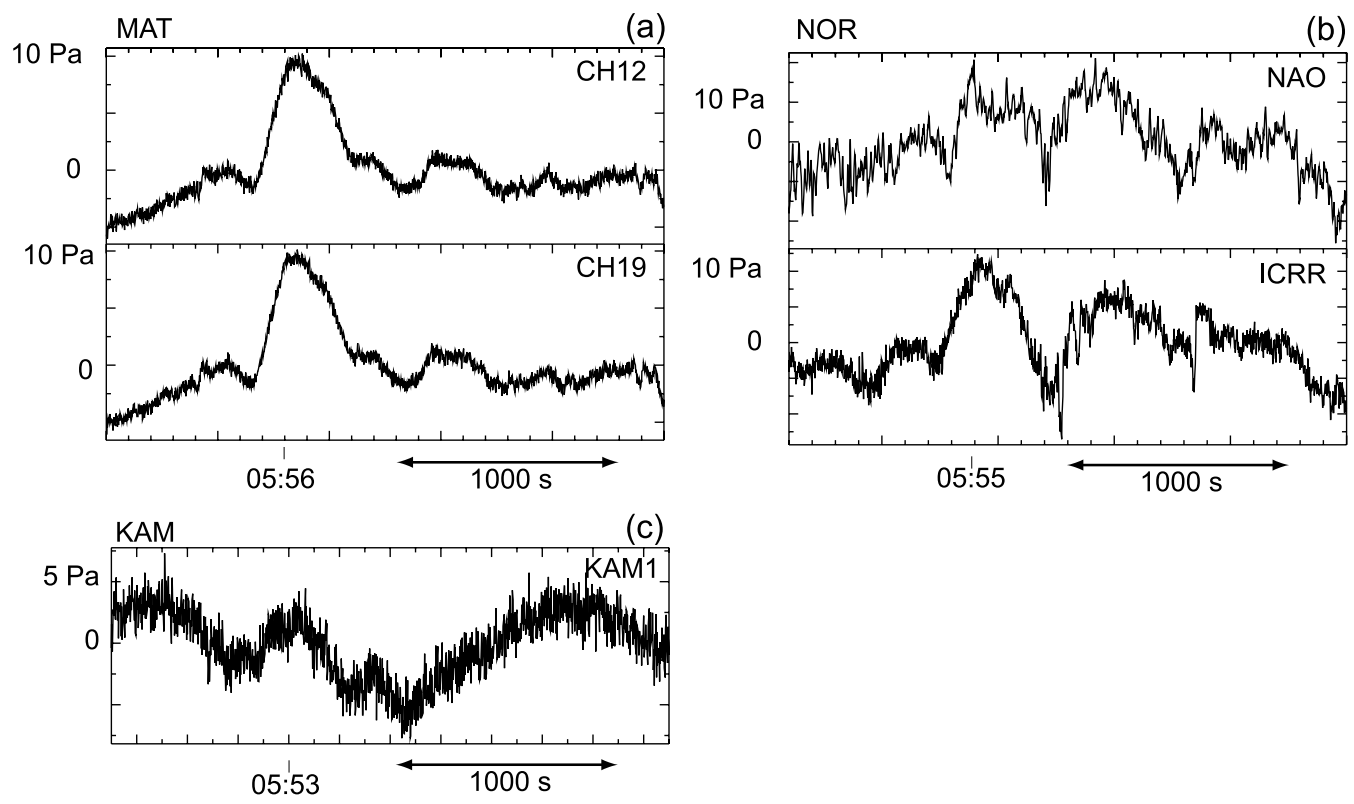

(c)
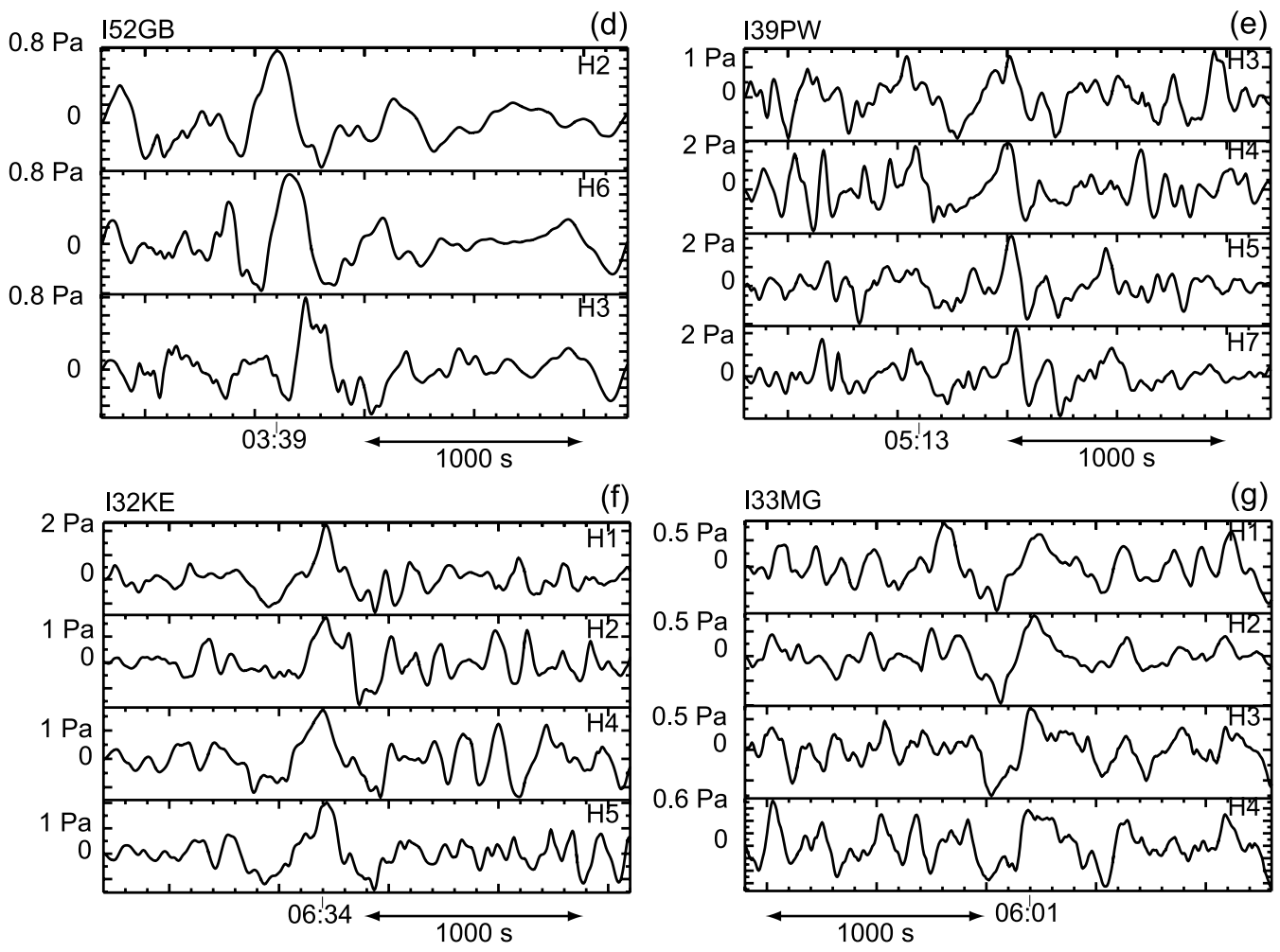

Figure 2. Microbarograph records at four Japanese stations: (a) MAT (Matsushiro Seismological Observatory), (b) NAO (Norikura National Astronomical Observatory) and ICRR (Institute for Cosmic Ray Research, University of Tokyo), and (c) KAM (Kamioka Station, DPRI, Kyoto University). Microbarograph records at four IMS stations: (d) I52GB (Diego Garcia), (e) I39PW (Palau), (f) I32KE (Kenya), and (g) I33MG (Madagascar). The time span covers $2400 \mathrm{~s} \mathrm{(40} \mathrm{min).} \mathrm{The} \mathrm{recorded} \mathrm{amplitude}$ and the approximate arrival time of the first compression peak are indicated for the respective stations in Table 1.

in Figure 2f. A good coherency of waveforms with periods of $\sim 400 \mathrm{~s}(\sim 6-7 \mathrm{~min})$ can be seen between all fourchannel records during $700 \mathrm{~s}$ around 0634 . The waves arrive at a group velocity of about $314 \mathrm{~m} / \mathrm{s}$, and the first compression peak has the amplitude exceeding 1-2 Pa. Figure $2 \mathrm{~g}$ shows the waveforms obtained at Madagascar (I33), indicating a rather good coherency between four channels during the time interval of about $600 \mathrm{~s}$ around 
Table 1. Location of the Barograph Stations With Arrival Times and Recorded Amplitudes of Acoustic-Gravity Waves From the 2004 Sumatra-Anderman Earthquake ${ }^{\mathrm{a}}$

\begin{tabular}{|c|c|c|c|c|c|c|c|}
\hline Station & $\begin{array}{c}\text { Latitude } \\
\left({ }^{\circ} \mathrm{N}\right)\end{array}$ & $\begin{array}{c}\text { Longitude } \\
\left({ }^{\circ} \mathrm{E}\right)\end{array}$ & $\begin{array}{c}r_{0} \\
(\mathrm{~km})\end{array}$ & $\begin{array}{c}r \\
(\mathrm{~km})\end{array}$ & $\begin{array}{l}\text { Azimuth } \\
\text { (degrees) }\end{array}$ & $\begin{array}{l}\text { Arrival Time } \\
\text { (on } 26 \text { Dec.) }\end{array}$ & $\begin{array}{c}\text { Amplitude } \\
(\mathrm{Pa}) \\
\end{array}$ \\
\hline MAT & 36.54 & 138.21 & 5673 & 5693 & 46.9 & 0556 & 9.0 \\
\hline ICRR & 36.11 & 137.55 & 5597 & 5619 & 47.1 & 0555 & 12.0 \\
\hline NAO & 36.12 & 137.55 & 5596 & 5619 & 47.1 & 0555 & 15.0 \\
\hline KAM & 36.28 & 137.33 & 5591 & 5610 & 46.8 & 0553 & 7.0 \\
\hline I52GB & -7.38 & 72.48 & 2860 & 2726 & 245.7 & 0339 & 0.8 \\
\hline $\mathrm{I} 33 \mathrm{MG}$ & -19.01 & 47.31 & 5863 & 5730 & 240.3 & 0601 & 0.8 \\
\hline I32KE & -1.24 & 36.83 & 6590 & 6312 & 264.7 & 0634 & 2.0 \\
\hline I39PW & 7.54 & 134.55 & 4297 & 4564 & 85.2 & 0513 & 2.0 \\
\hline
\end{tabular}

${ }^{a}$ Here $r_{0}$ and $r$ are the distances from the USGS epicenter and the center of the $2 U$ zone.

0601 with a group velocity of about $310 \mathrm{~m} / \mathrm{s}$. The apparent period between the first and second compression peaks is about $360-400 \mathrm{~s}(\sim 6-7 \mathrm{~min})$, and amplitudes reaches $\sim 0.8 \mathrm{~Pa}$. The last one shown in Figure 2e indicates fourchannel records obtained at Palau (I39). Some consistency may be identified during the time interval of about $800 \mathrm{~s}$ after 0513 , suggesting a group velocity of $298 \mathrm{~m} / \mathrm{s}$. The apparent period is about $400 \mathrm{~s}(\sim 6-7 \mathrm{~min})$, and the peak amplitude reaches 1-2 $\mathrm{Pa}$. The extracted waveforms appear somewhat different from those recorded at the other 3 IMS stations, in spite of the same frequency response of the sensors. This might be due to the different azimuth of the Palau station with respect to the source from the other stations, and will be discussed in the next section after waveform modeling has been made to the observed records. The group velocities observed at the above stations are found consistent with those expected from their theoretical dispersion curves (Figure S2). ${ }^{1}$ All the observations are summarized in Table 1.

\section{Waveform Modeling}

[8] We perform waveform modeling for the recorded barograms in order to confirm that the recorded waves can be interpreted as low-frequency acoustic-gravity waves propagating through the lower atmosphere from the source region. From this modeling, we also aim at clarifying some aspect of the source characteristics of the 2004 SumatraAndaman earthquake. This procedure calculates synthetic waveforms using forward modeling, and incorporates the dynamic response of the temperature structure in the lower atmosphere to various source parameters, as described below.

\subsection{Dynamic Response of the Atmosphere}

[9] The sudden vertical movement of the ground or the sea surface can excite atmospheric pressure perturbations which will propagate first upward or obliquely toward the upper atmosphere and after some time spread horizontally as acoustic and gravity waves in the lower atmosphere. These propagation patterns depend strongly on their wavelength, as indicated by recent numerical simulations [e.g., Artru et al., 2005; Shinagawa et al., 2007]. Although the theory of pressure waves propagating in the lower atmosphere can be traced back to several early studies, more advanced studies incorporating a realistic atmospheric ther-

\footnotetext{
${ }^{1}$ Auxiliary materials are available in the HTML. doi:10.1029/ 2008JB005710.
}

mal structure have been made later by Press and Harkrider [1962], Pfeffer and Zarichny [1963], Harkrider [1964], Harkrider and Press [1967], and others. The above studies include the phase and group velocity dispersion curves for different acoustic-gravity modes, and the dynamic spectral amplitude response of the lower atmosphere. For calculating synthetic waveforms in the present study, we essentially follow the formulations and some results by Harkrider [1964], which have been somewhat modified [Mikumo, 1968] to include extended sources over the ground for the case of the 1964 great Alaskan earthquake. The pressure perturbation that would be recorded at a station in the far field compared with the source dimension and the wavelength can be written in the frequency domain as [Mikumo, 1968], assuming a linear system coupled between the ground or sea surface and the atmosphere

$$
[p(r, 0, t)]_{A j}=c(r / R \sin \theta)^{1 / 2}(1 / 2 \pi) \int F(\omega) \exp [-i \varphi(\omega)] d \omega
$$

$$
\begin{aligned}
& F(\omega)=S(\omega) D(\omega) A(\omega) B(\omega), \text { and } \\
& \varphi(\omega)=\varphi s(\omega)+\varphi_{D}(\omega)+\varphi_{A}(\omega)+\varphi_{B}(\omega),
\end{aligned}
$$

where $S(\omega), D(\omega), A(\omega)$, and $B(\omega)$ are the source time factor, source finiteness factor, the atmospheric transfer function, and the barograph response, and $\varphi(\omega) \mathrm{s}$ are their phase responses, respectively. Here $(r / R \sin \theta)^{1 / 2}$ is the approximate curvature correction factor for the effect of energy spreading over a spherical surface instead of a flat surface, with the distance to the station $r$, the earth's radius $R$ and the spherical colatitude $\theta$ of the station. Here $c=2(2 / \pi)^{1 / 2}$, which is a numerical constant derived from Harkrider's [1964] formulations. The atmospheric transfer function $A(\omega) \exp \left[-i \varphi_{A}(\omega)\right]$ may be defined as

$$
A(\omega)=A_{A j}(\omega) k_{j}^{1 / 2} / \omega, \varphi_{A}(\omega)=\omega r / C_{j}(\omega)-\pi / 4
$$

where $k$ is the horizontal wave number and $j$ indicates different mode number of acoustic-gravity waves. On the basis of the standard ARDC model of the lower atmosphere (Figure S1), Harkrider [1964] has computed the phase velocity $C_{j}(\omega)$ (Figure S2) and the dynamic response of the lower atmosphere $A_{A j}(\omega)$ to a surface source and receiver (Figure S3). The above ARDC model has two temperature minima at the tropopause at an altitude of about $15 \mathrm{~km}$ and 


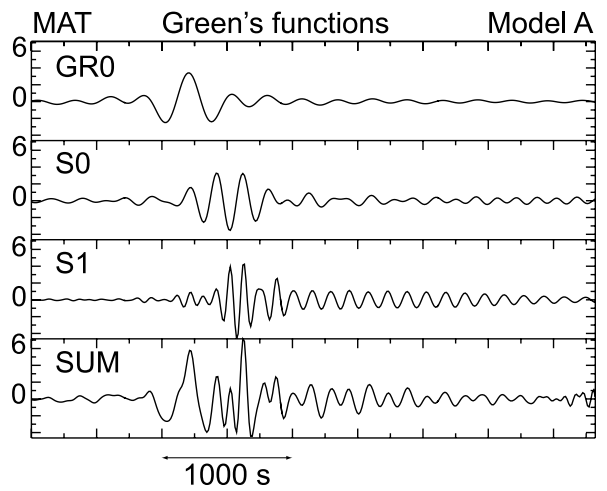

Figure 3. Green's functions for acoustic $\left(S_{0}\right.$ and $\left.S_{1}\right)$ and gravity modes $\left(G R_{0}\right)$ to MAT $(r=5693 \mathrm{~km})$ from a point source placed at the center of the $2 U$ region in Figure 4 . The amplitude is indicated as an arbitrary scale.

at the mesopause at about $85 \mathrm{~km}$, and then the temperature gradually increases up to the thermosphere. This is essentially similar to the recent empirical atmospheric model MSISE [Hedin, 1991] in the lower atmosphere without mass density distribution. The model was approximated by 39 isothermal horizontal layers terminated with an isothermal half-space or with the free surface at an altitude of $220 \mathrm{~km}$ [Harkrider, 1964], which are referred to as Model A (half-space) and Model B (free surface) in the present paper. Sound velocity at all these heights can be estimated from the square root of the temperature. The calculated two functions include the fundamental and first higher-gravity modes $G R_{0}$ and $G R_{1}$ and the fundamental, the first and second higher-acoustic modes $S_{0}, S_{1}$, and $S_{2}$ for Model A. It is to be mentioned that $G R_{0}$ has spectral amplitudes over a range from 4.5 to $14 \mathrm{~min}$ and $S_{0}$ covers from 2 to $4.5 \mathrm{~min}$, while there are no long-period cutoffs in Model B. In both cases, there are minor fluctuations in the amplitude and period range due to seasonal wind structures. The bandpass filtering applied for the original IMS data given in the previous section was based on Model A to retrieve low-frequency acoustic-gravity waves. We calculate here the Green's functions in Model A for the gravity and acoustic modes propagating to the MAT station $(r=5693 \mathrm{~km})$ from a point source placed at the center of the $2 U$ region (see Figure 4), which is assumed to have an upward unit impulse time function. The calculated waveforms are shown in Figure 3, where $G R_{1}$ and $S_{2}$ are not plotted here because of their negligible amplitudes. These waves with periods between 3 and 5 min may be interpreted as acoustic and gravity waves trapped between the lower thermosphere and the earth's surface [Shinagawa et al., 2007]. The bottom trace shows the sum of the three modes, indicating the arrival of large amplitude waves with an initial period of about $360 \mathrm{~s}(\sim 6 \mathrm{~min})$.

\subsection{Coseismic Vertical Deformation}

[10] The 2004 Sumatra-Andaman earthquake produced large-scale coseismic crustal deformation over the extensive source region. Detailed analyses of near- and far-field GPS data revealed coseismic slip distribution over the fault plane from the northern Andaman Islands down to the northwestern Sumatra region extending for longer than $1500 \mathrm{~km}$
[Vigny et al., 2005; Banerjee et al., 2005, 2007; Subarya et al., 2006; Hashimoto et al., 2006; Chlieh et al., 2007]. The slip estimated from these analyses ranges from several to $20 \mathrm{~m}$ on a downdip fault plane with a width of $150-180 \mathrm{~km}$ and a dip from $8^{\circ}$ to $15^{\circ}$ at depths between a few to $40 \mathrm{~km}$. Preliminary calculations based on the slip over the fault plane suggest large uplift exceeding 6-7 $\mathrm{m}$ and subsidence of $2-3 \mathrm{~m}$ on the seafloor or on islands in the Nicobar region [Bilham et al., 2005; Heki et al., 2006]. The ground uplift and subsidence on islands have been surveyed by detailed field leveling measurements and with satellite imagery in some regions [Meltzner et al., 2006; Rajendran et al., 2007], indicating vertical displacements ranging from several tens of $\mathrm{cm}$ to $3 \mathrm{~m}$. We consider the values estimated from the field surveys to represent the displacements near the pivot line between the zones of uplift and subsidence. We tentatively divide the entire source region subjected to the coseismic deformation into eight zones as shown in Figure 4, which include the presumed uplifted $(1 U-4 U)$ and subsided

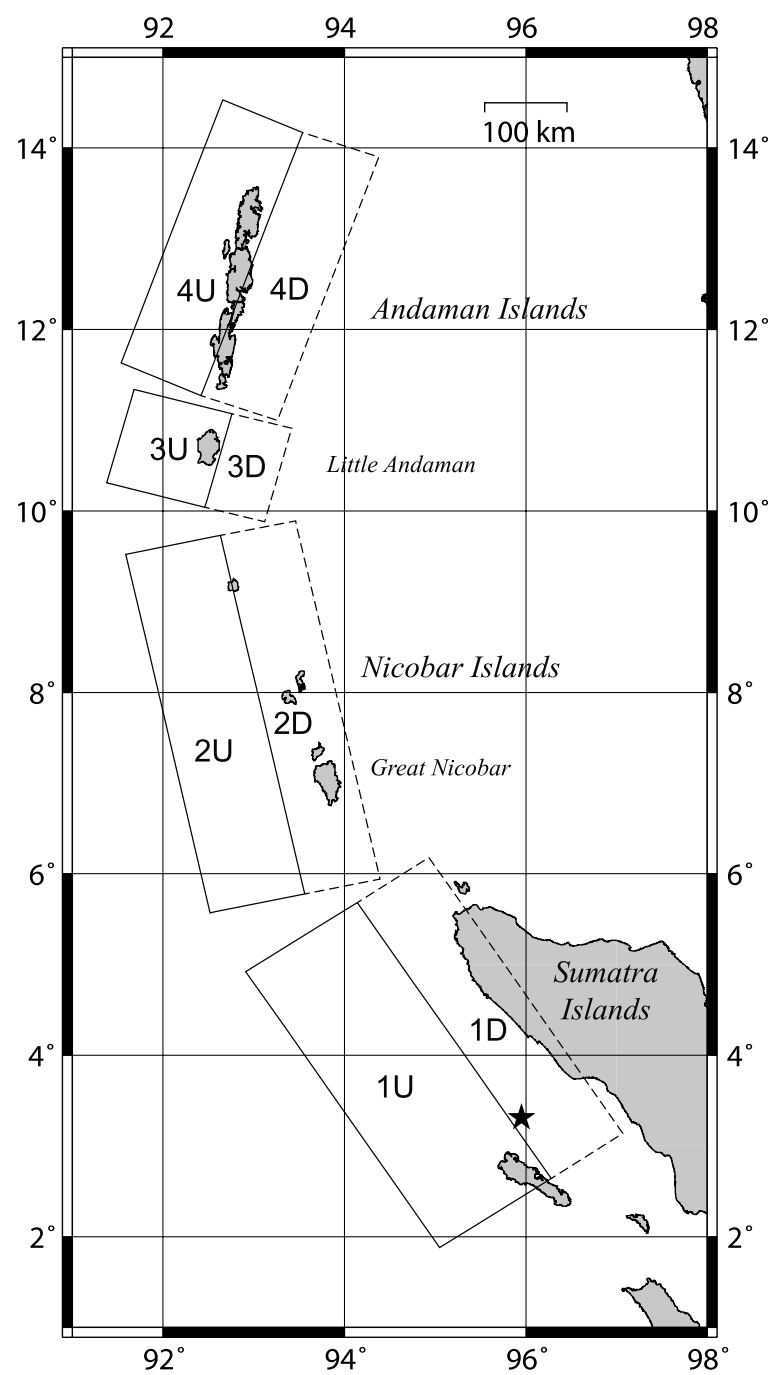

Figure 4. Presumed uplifted zones $(1 U-4 U)$ and subsided zones $(1 D-4 D)$ due to the 2004 Sumatra-Andaman earthquake. The boundary line separating the zones of uplift and subsidence approximately follows the pivot line estimated by field surveys [Meltzner et al., 2006]. 
$(1 D-4 D)$ zones. The boundary line separating these zones approximately follows the pivot line shown by Meltzner et al. [2006].

[11] We note that most of the source region lies in the ocean. Large submarine thrust faulting would produce coseismic uplift and subsidence on the sea bottom, and then the deformation would cause swelling and depression of the sea surface. Theoretical studies [Kajiura, 1963, 1970] on tsunami generation show that if the wavelength of the coseismic deformation is much longer than the water depth and if the deformation takes place within a few minutes, the sea surface behaves almost exactly like the sea bottom deformation. These conditions are met in the present case with the wavelength of deformation over 150-200 km across the E-W profile (See Figure 4) with respect to the water depth of 3000-4000 $\mathrm{m}$ in the Indian Ocean. This behavior has been confirmed later by numerical simulations for the swelling height of the sea surface as functions of different wavelengths and of the ratio of the elapsed time to the source process time (T. Saito and T. Furumura, Three dimensional simulations of tsunami generation and propagation: The Kuril Islands event of 13 January 2007, submitted to J. Geophys. Res., 2007). These studies indicate that the vertical displacement of the sea surface and its time constant will be almost the same as that of the sea bottom under the above conditions.

[12] If the coseismic uplift or subsidence of the ground or the sea surface is modeled as,

$$
z_{0}(r, t)=(a / 2)[1-\cos (\pi t / \tau)](\text { for } t<\tau, r<L, W),
$$

where $a$ and $\tau$ are the vertical displacement and its time constant, respectively, then the corresponding upward particle velocity of the air $w_{0}$ at $z=0$ is equal to that of the ground or the sea surface $w_{0}=\dot{z}_{0}(r, t)=(\pi a / 2 \tau) \sin (\pi t / \tau)$. The pressure perturbation $p_{0}$, ambient air density $\rho_{0}$ and sound velocity $c_{0}$ near the ground surface can be approximately related by $p_{0}=\rho_{0} c_{0} w_{0}$, if the ratio of the time constant of coseismic vertical deformation to the local Brunt period $(\sim 340 \mathrm{~s})$ is less than 0.3 , and if the phase velocity of the expanding deformation is much faster than the sound velocity [Watada et al., 2006]. In this case, the source time factor in the frequency domain in equation (2) is given by

$S(\omega)=\left(\rho_{0} c_{0} a / 2 \tau\right) \sin (2 \omega \tau) /\left[(\omega \tau / \pi)^{2}-1\right]$ and

$\varphi_{S}(\omega)=\exp (-i \omega \tau)$.

The time dependence of coseismic deformation can be assumed in different forms other than the above, but it has been tested that different assumptions do not yield significantly different synthetic waveforms in the frequency range lower than $1 / \tau$.

[13] We denote the dimension of a rectangle source for each zone $j$ by the length $2 L_{j}$ and the width $2 W_{j}$, and the horizontal expanding velocity of the source area by $v$, then the source finiteness factor in equation (2) can be written as

$D(\omega)=4 L_{j} W_{j}\left|\left\{\sin \left(\omega T_{L}\right) /\left(\omega T_{L}\right)\right\}\left\{\sin \left(\omega T_{W}\right) /\left(\omega T_{W}\right)\right\}\right|$ and

$\varphi_{D}(\omega)=0$ if the distance to the station $r$ is measured from the center of the rectangular source, where [Mikumo and Bolt, 1985]

$$
T_{L}=L j[1 / v-\cos \beta / C j(\omega)], T w=W j \sin \beta / C j(\omega)
$$

and $\beta$ is the azimuth from the source to the station with respect to the expanding direction of the source area. We also include the barograph response $B(\omega)$ appropriate to the station under investigation.

\subsection{Estimate of Source Parameters}

[14] To calculate synthetic waveforms of the atmospheric acoustic-gravity waves, we assign various earthquake source parameters given above to look for a reasonable fit to the recorded waveforms at each station. These parameters are (1) the source location and dimensions of the uplifted and subsided zones $L_{j}$ and $W_{j}(j=1 \sim 8)$, (2) the horizontal expanding velocity of the source $v$ from the epicenter (which may be approximated by the rupture velocity on the fault plane), (3) the average vertical displacements $D_{j U}$ and $D_{j D}(j=1 \sim 4)$ on each of the uplifted and subsided zones, and (4) the risetime of the displacement $\tau$ (tentatively assumed to be the same in eight zones, but will be discussed later). We first calculate synthetic waveforms for MAT, because the station shows the most unique and convincing observed waveforms over a wide frequency range in a less disturbed time series. Figure 5 shows the synthetic waveforms coming from the eight zones, respectively. Each of these waveforms is the sum of $G R_{0}, S_{0}$, and $S_{1}$ modes from Models A and B. As a first test, the displacements are tentatively given an equal unit amplitude (e.g., $D_{j U}=1 \mathrm{~m}$ for the uplifted zones, and $D_{j D}=-0.5 \mathrm{~m}$ for the subsided zones), with $\tau=1 \mathrm{~min}$ and $v=2.5 \mathrm{~km} / \mathrm{s}$. It is easily noticed that the wave amplitudes from the 4 subsided zones $(1 D \sim$ 4D) (b and d) are much smaller than those from the 4 uplifted zones $(1 U \sim 4 U$ ) (a and c). Since Model B has no long-period cutoffs in the phase and group velocities and in the dynamic spectral amplitude, we tentatively assume it to be $240 \mathrm{~min}$, which gives longer-period waves than Model A possibly because all energies are confined between the free surface located at $220 \mathrm{~km}$ and the earth's surface.

[15] As a next step, we calculate a large number of synthetics for Models A and B for various combinations of displacements $D_{j U}$ and $D_{j D}$, risetimes $\tau$, and expanding velocities $v$. In this case, we tested for a variety of the source parameters in the range of $D_{j U}=1 \sim 6 \mathrm{~m}, D_{j D}=-0.5 \sim-3 \mathrm{~m}$, $(j=1 \sim 4), \tau=0.5 \sim 2.5 \mathrm{~min}$ (in equation $(4-2)$ ) and $v=1.7 \sim$ $2.9 \mathrm{~km} / \mathrm{s}$. Although a large number of synthetics have been produced from these combinations, only the cases that can be compared with the recorded waveforms are shown here. Figures $6 \mathrm{a}$ and $6 \mathrm{c}$ show the synthetics for those from the above 8 zones, with four different displacements $D_{2 U}$ ranging from 1 to $6 \mathrm{~m}$ and $D_{2 D}=-(1 / 2) D_{2 U}$, and fixing other displacements $D_{j U}=1 \mathrm{~m}$ and $D_{j D}=-0.5 \mathrm{~m}(j=1,3,4)$ with $\tau=1.0 \mathrm{~min}$ and $v=2.5 \mathrm{~km} / \mathrm{s}$. The synthetics in Figures $6 \mathrm{~b}$ and $6 \mathrm{~d}$ show the cases for four different risetimes $\tau=0.5-2.0 \mathrm{~min}$ with a fixed displacement $D_{2 U}=4 \mathrm{~m}$ and $D_{2 D}=-2 \mathrm{~m}$. Comparing the synthetic waveforms shown in Figures $6 \mathrm{~b}$ and $6 \mathrm{~d}$, we see that the risetimes around $0.5 \mathrm{~min}$ produce sharper waveforms and those longer than $1.5 \mathrm{~min}$ predict much gentler waveforms than were observed. The risetimes much shorter than $0.5 \mathrm{~min}$ or longer than $2.0 \mathrm{~min}$ 

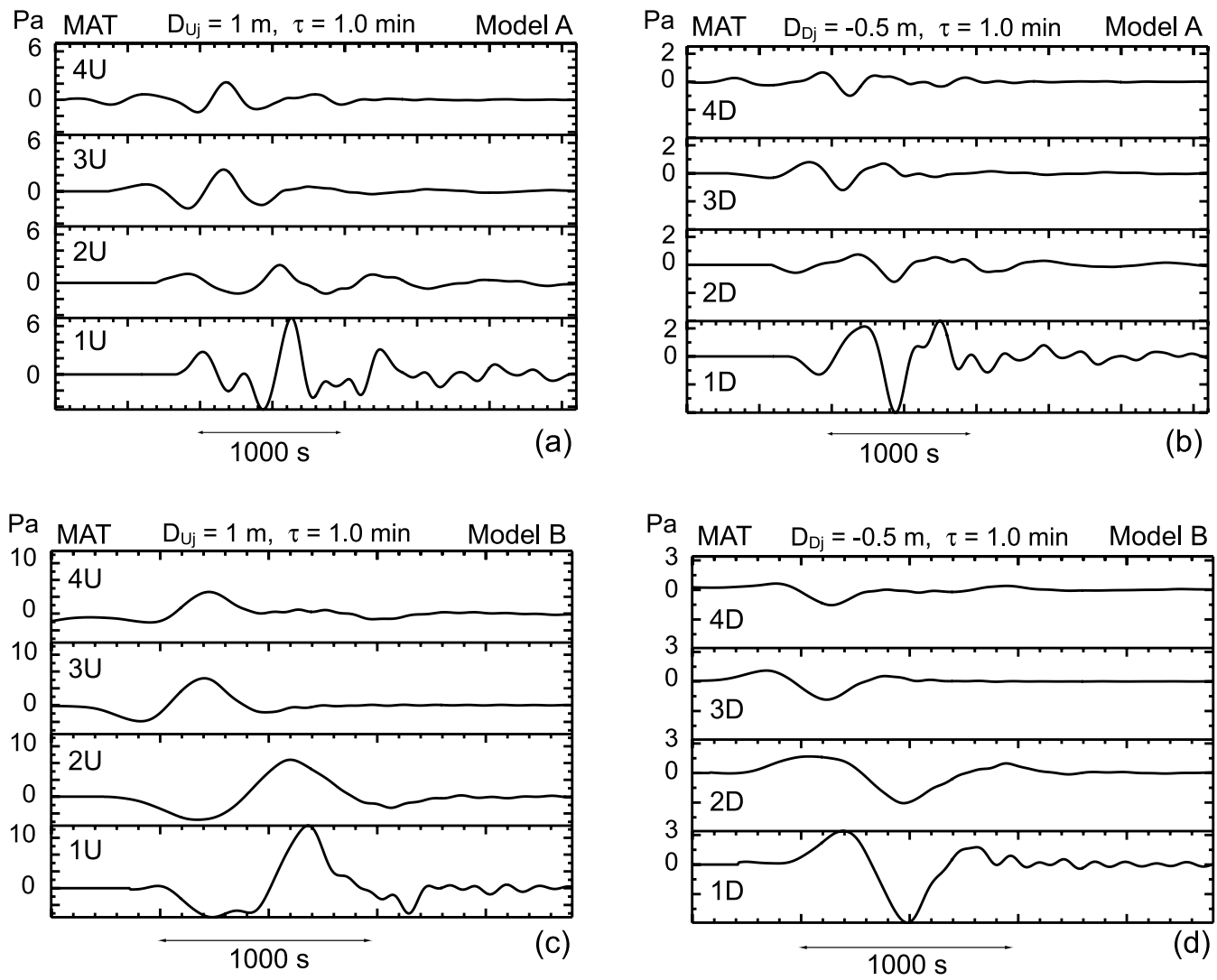

Figure 5. Synthetic waveforms for MAT coming from each of eight zones: (a) and (c) the uplifted zone and (b) and (d) the subsided zones. $D_{j U}$ and $D_{j D}$ are assumed displacements, and $\tau$ is an assumed risetime. Models A and B correspond to two different atmospheric models (see text).

do not fit the recorded waveforms well. It is possible that these risetimes could be longer in the northern source region, because slower slip has been suggested in the northern segments from some of tsunami data [e.g., Lay et al., 2005; Singh et al., 2006]. However, this cannot be well resolved from the present analysis due to large coseismic uplift in the $2 U$ zone which has masked this possibility in the northern region.

[16] We made similar calculations for different expanding velocities ranging between $1.7 \sim 2.9 \mathrm{~km} / \mathrm{s}$, referring to seismic [Lay et al., 2005] and tsunami [Tanioka et al., 2006] data analysis, with $D_{2 U}=4 \mathrm{~m}$ and $\tau=1 \mathrm{~min}$ (for Models A and B) as shown in Figure 6e and 6f. Although these yield quite similar waveforms with decreasing amplitudes with increasing velocities, $v=2.5 \mathrm{~km} / \mathrm{s}$ or even little bit faster (Model A) appears to give theoretical amplitude comparable to the observed one. However, this cannot be conclusive because of trade-off between increasing displacements. The arrival time of the first compression peak in this range of velocities shows only a small difference around $1 \mathrm{~min}$. This may be mainly because the source expanding velocity is much faster than the sound speed near the earth's surface, and partly because the synthetic waveforms are strongly affected by large displacement in the $2 U$ zone. A long distance from the source region to MAT as compared with the source dimension may be another factor. Among various combinations of these source parameters, $D_{2 U}=4 \sim 6 \mathrm{~m}$ and $D_{2 D}=-2 \sim-3 \mathrm{~m}$, risetimes $\tau=1.0 \sim 1.5 \mathrm{~min}$, and $v \sim$
$2.5 \mathrm{~km} / \mathrm{s}$ may be best compared with the observed waveform and its amplitude recorded at the MAT station. We use these parameters to evaluate synthetic waveforms for the other recording stations.

\subsection{Comparison Between the Recorded and Synthetic Barograms}

[17] Comparisons of the waveforms recorded at the eight stations with the corresponding synthetic waveforms are shown in Figure 7, where these waveforms are aligned on the time for the best fit at each of the stations. In Figures 7a and $7 \mathrm{~b}$, four different synthetics for MAT are given in the middle and bottom traces for Models A and B. The maximum theoretical amplitudes for the two different cases in Figure 7a (Model A) are 15.4 and $13.3 \mathrm{~Pa}$, respectively. On the other hand, the maximum recorded amplitude at the station MAT is $9 \mathrm{~Pa}$, which is quite close to the theoretical estimates but still less than these values. We notice that the waveform of the first large compression peak may be well explained by any of above 4 synthetics, but for Model A, the first peak is preceded by a large dilatation precursor and is also accompanied by a large second peak. These might be due to some truncation effects at long-period cutoff for mode $\mathrm{GR}_{0}$ in the spectral amplitude. For Model B (b), on the other hand, these effects are not apparent and seem to provide a reasonable fit to the recorded waveforms, but the theoretical amplitudes exceed $20 \mathrm{~Pa}$. The same situations can be found for NOR (ICRR) (c), where the observed maximum amplitude is $12 \mathrm{~Pa}$ for the theoretical one of $15 \mathrm{~Pa}$ 

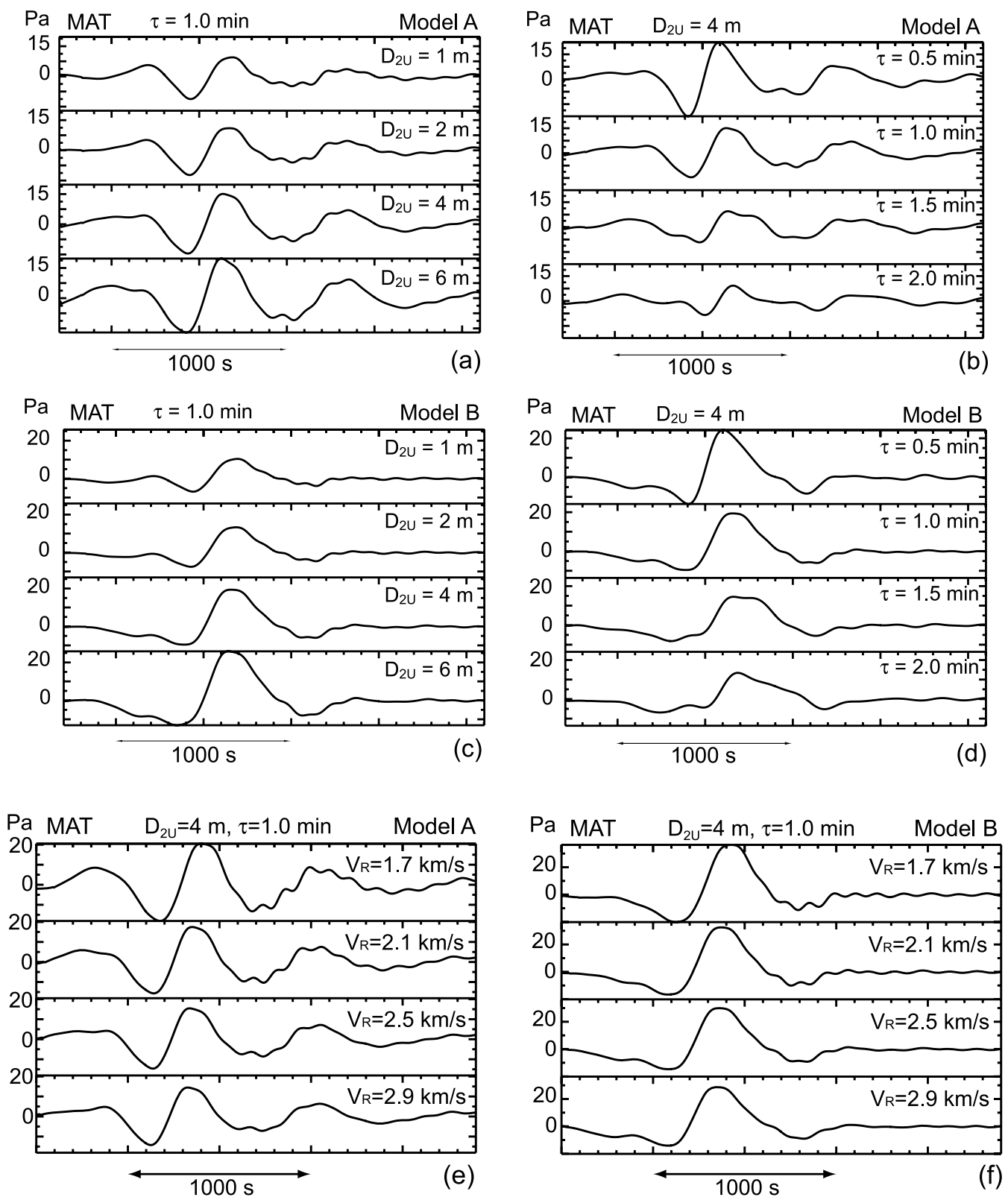

Figure 6. (a) and (c) Synthetic waveforms for MAT for four assumed displacements from $D_{2 U}$ with a fixed risetime of $1 \mathrm{~min}$. (b) and (d) Synthetic waveforms for MAT for four assumed risetimes with a fixed displacement $D_{2 U}=4 \mathrm{~m}$ and $D_{2 D}=-2 \mathrm{~m}$. Displacements in other zones are fixed to be $D_{j U}=1 \mathrm{~m}$ and $D_{j D}=-0.5 \mathrm{~m}$. The source expanding velocity $v$ is assumed to be $2.5 \mathrm{~km} / \mathrm{s}$. (e) and (f) Synthetic waveforms for MAT for four assumed horizontal expanding velocities ranging from 1.7 to $2.9 \mathrm{~km} / \mathrm{s}$, with a fixed displacement as in Figures $6 \mathrm{~b}$ and $6 \mathrm{~d}$ and a fixed risetime of $1 \mathrm{~min}$.

from Model A, while Model B gives $20 \mathrm{~Pa}$ for the same source parameters. This situation is almost the same for the other NOR (NAO) station (not shown here). It is to be noted that the synthetics for the two NOR stations include an approximation because the stations are not located at the sea level but at a high altitude of $2789 \mathrm{~m}$. Our calculations do not include the effects of this altitude. The theoretically expected amplitude from Model A for KAM (d) is about $15 \mathrm{~Pa}$, while the observed peak-to-peak amplitude is $\sim 7 \mathrm{~Pa}$. Because the KAM record is preceded and followed by lowfrequency disturbances, it is difficult to compare it exactly with the theoretical amplitude. From the above comparisons at the Japanese stations, we see that two cases for $D_{2 U}=4 \mathrm{~m}$ with $\tau=1.0 \mathrm{~min}$ and for $D_{2 U}=6 \mathrm{~m}$ with $\tau=1.5 \mathrm{~min}$ for Model A are almost equally possible to explain the recorded waveforms.

[18] Figures $7 \mathrm{e}-7 \mathrm{~h}$ show comparisons between the recorded and synthetic waveforms for the 4 IMS stations. As mentioned before, since the barograph response at these stations has a rapid decay for frequencies lower than $0.02 \mathrm{~Hz}$, we incorporate this frequency response to calculate the synthetic waveforms. For this reason, the synthetics are a 

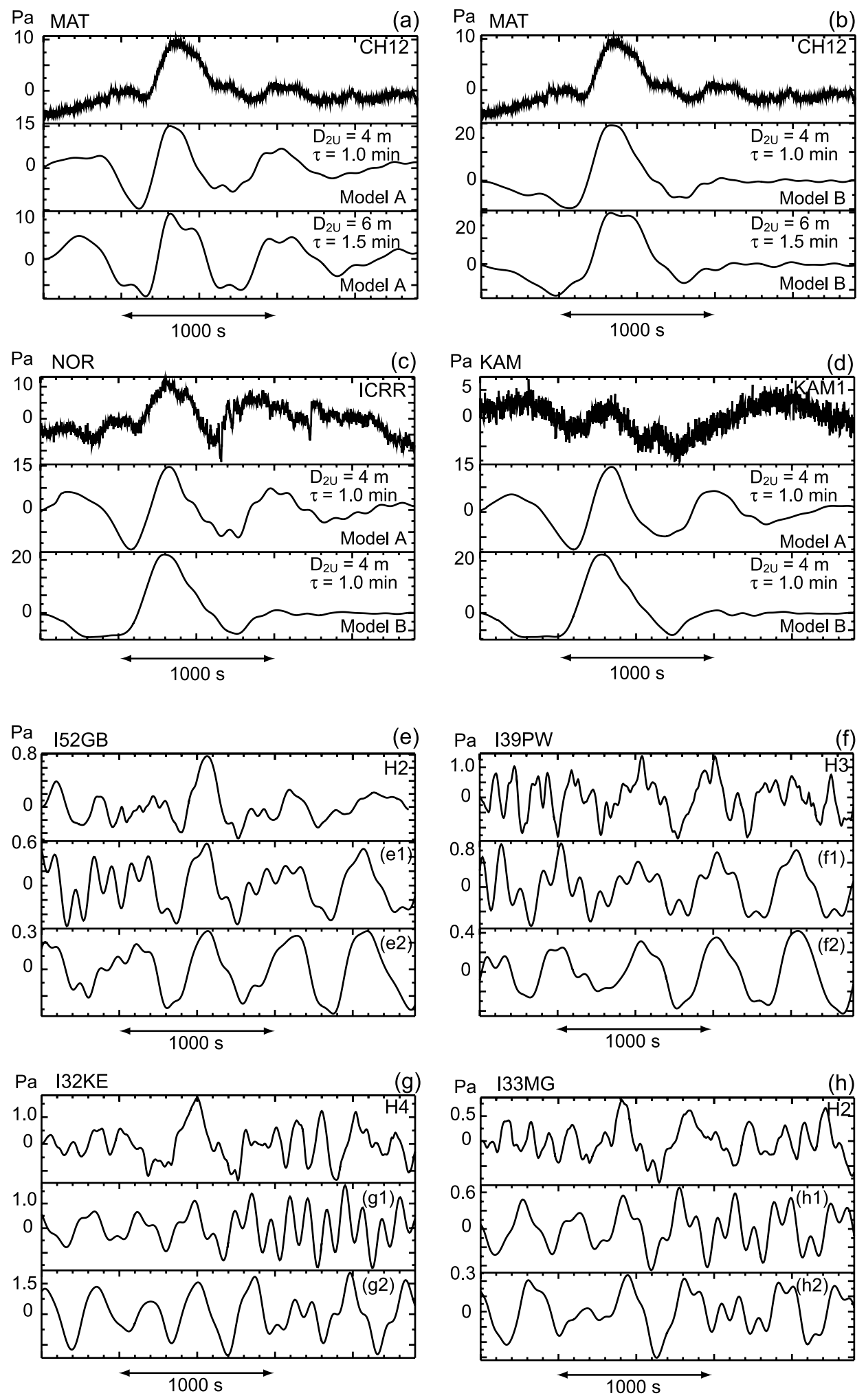

Figure 7. $(\mathrm{a}-\mathrm{c})$ Comparison between the recorded and two synthetic waveforms at four Japanese stations, where these waveforms are aligned on the time for the best fit at each of the stations. $(\mathrm{d}-\mathrm{g})$ Comparison between the recorded and two synthetic waveforms at four IMS stations, where these waveforms are aligned on the time for the best fit at each of the stations. Synthetic waveforms (e1), (f1), (g1), and (h1) for $D_{2 U}=4 \mathrm{~m}$ and $\tau=1.0 \mathrm{~min}$. Synthetic waveforms (e2), (f2), (g2), and (h2) for $D_{2 U}=6 \mathrm{~m}$ and $\tau=1.5 \mathrm{~min}$. The uppermost trace for each station shows the recorded waveform, and the middle and bottom traces indicate the two synthetic waveforms, respectively. Assumed displacements $D_{2 U}$ and risetimes $\tau$ are indicated in each of the insets for the synthetics, with $D_{2 D}=-(1 / 2) D_{2 U}$ and $v=2.5 \mathrm{~km} / \mathrm{s}$. 
low-frequency-diminishing version of Model A. We find a reasonably good similarity in the waveforms for the first compression peak between the record and synthetics for I52GB (Figure 7e), I32KE (Figure 7g), and I33MG (Figure 7h), and for a wave train including three peaks for I39PW (Figure 7f). The theoretically expected amplitudes (0.6$1.2 \mathrm{~Pa}$ ) in these synthetics are almost comparable to the recorded amplitudes at I32KE (Figure 7g), I39PW (Figure 7f) and I33MG (Figure $7 \mathrm{~h}$ ) for the first model parameters $\left(D_{2 U}=4 \mathrm{~m}\right.$ and $\tau=1.0 \mathrm{~min}$ ) except for I52GB (Figure 7e). On the other hand, the second case $\left(D_{2 U}=6 \mathrm{~m}\right.$ and $\left.\tau=1.5 \mathrm{~min}\right)$ predict significantly smaller amplitudes for the three stations (Figures 7e, 7f, and 7h).

[19] We see that the above comparison between the recorded and synthetic waveforms and amplitudes at the Japanese and IMS stations suggests that $D_{2 U}=4 \mathrm{~m}$ with $\tau=$ $1.0 \mathrm{~min}$ or little bit longer risetime and $v=2.5 \mathrm{~km} / \mathrm{s}$ may be most preferable.

\section{Discussion and Conclusions}

[20] The maximum pressure perturbation $\mathrm{p}_{0}$ at the source region $(2 U)$ can be roughly evaluated as $27.58 \mathrm{~Pa}$ for $\rho_{0}=$ $1.293 \times 10^{-3} \mathrm{gr} / \mathrm{cm}^{3}, \mathrm{c}_{0}=320 \mathrm{~m} / \mathrm{s}$, and $\mathrm{w}_{0}=4 \mathrm{~m} / 1 \mathrm{~min}$ or $6 \mathrm{~m} / 1.5 \mathrm{~min}$. Incorporating the pressure perturbation at all source regions, we have estimated the absolute amplitude of the synthetic barograms for all the stations through equations (1)-(5) in section 3 . It is found that the maximum amplitudes recorded at these stations are almost comparable to the theoretical estimates but still leave some discrepancies. This may be due partly to large atmospheric disturbances around the time of the earthquake prevailing over a wide region, which may have considerably suppressed the signal/noise ratio of observations at all the stations. Actually, the amplitudes recorded at nearby stations differ from each other. In addition, there are some other uncertainties to estimate the exact theoretical absolute amplitude such as wave attenuation and fluctuations in the spectral amplitudes due to thermal and wind structures in the lower atmosphere, which could deviate the actual atmosphere from the standard ARDC atmospheric model. For these reasons, we did not make further attempts to reconcile the discrepancies.

[21] In calculating the synthetic waveform, the upper atmospheric structures such as represented by the CIRA model [e.g., Yeh and Liu, 1974] or the MSISE model [Hedin, 1991] with mass density distribution are not taken into considerations, assuming that the upper atmospheric structure would not significantly affect the waveform of acoustic-gravity waves recorded here. Instead, in the present article, we consider two possible thermal structures above an altitude of $220 \mathrm{~km}$, one continuing up to an isothermal half-space (Model A) [Harkrider, 1964] and the other terminating with the free surface (Model B) [Press and Harkrider, 1962; Harkrider and Press, 1967]. The two different models provide somewhat different synthetic waveforms at the stations, as shown in Figures 5, 6, and $7 \mathrm{a}-7 \mathrm{~d}$. Since the two models provide quite reasonable waveforms consistent with the long period, first compression peak on the records, we will not discuss further about their difference. However, Model A appears to be physically more plausible, because it indirectly includes part of a thermal structure in the upper atmosphere.
[22] It has now been demonstrated that the unusually lowfrequency atmospheric pressure perturbations recorded at eight Japanese and IMS stations can be interpreted as the acoustic-gravity waves produced by large coseismic vertical deformation over an extensive source region of the 2004 Sumatra-Andaman earthquake and propagated through the lower atmosphere to long distances up to $6500 \mathrm{~km}$. From the analysis of the low-frequency acoustic-gravity waves, we have been able to obtain an approximate estimate for the vertical displacements of coseismic uplift and subsidence, through comparisons between the observed barograms and the synthetic waveforms with theoretically expected amplitude, as shown in Figures 5-7. From the present analysis, it is possible to say that the coseismic average uplift in the source region $2 U$ corresponding to the south-central zone of the Andaman-Nicobar region could reach at least $4 \mathrm{~m}$, which may be much larger than that in the other regions, probably a few times larger. The above results are independent estimates obtained directly from the atmospheric pressure waves. This estimate appears much larger than that from geodetic or field data analysis [e.g., Subarya et al., 2006; Rajendran et al., 2007; Banerjee et al., 2007], but more or less consistent rather with indirect estimates [e.g., Bilham et al., 2005] and with qualitative comparison with the CID variation [Heki et al., 2006] based on a geodetic model [Banerjee et al., 2005]. It is to be noted that the northern half of the entire region appears to contribute a relatively small portion to the generation of the observed acoustic-gravity waves, because of smaller coseismic vertical deformation there. There leaves, however, another possibility that unexpectedly longer risetimes than assumed in the northern region would reduce the effects of possible significant vertical displacements, although the risetimes there have not been well resolved. Comparing the synthetic waveforms shown in Figures $6 \mathrm{a}-6 \mathrm{~d}$ with the recorded barograms in Figure 7, we see that the risetime of the coseismic deformation in the south-central zone may be in the range between 1.0 and $1.5 \mathrm{~min}$. This is another independent estimate from the acoustic-gravity waves, although the risetime in the northern source region has not been well resolved. It is to be emphasized that the risetime estimated here may be regarded as the time elapsed shortly before generating tsunami waves that propagated rapidly and caused significant damage around the source region. This estimate is significantly shorter than $3 \mathrm{~min}$ inferred from inversion of the tsunami waveforms based on tide gauge and satellite data [Fujii and Satake, 2007]. Our estimate corresponds to the initial swelling stage of the sea surface, while theirs would probably include its expanding stage into tsunami waves. The estimated range of our risetimes are similar to that for the 1964 great Alaskan earthquake $\left(M_{w}=\right.$ 9.0) [Mikumo, 1968] that also generated low-frequency atmospheric pressure waves from extensive coseismic crustal deformation.

[23] Acknowledgments. We are grateful to the following colleagues for their useful suggestions to the present study, T. Iyemori, K. Satake, T. Furumura, and K. Heki, and for cooperation in searching for microbarograph data, R. A. Uhrhammer, M. Hashimoto, H. Hashiguchi, T. Shimomai, S. Mori, H. Kanamori, R. Yamamoto, M. Hashizume, T. Murayama, and $\mathrm{N}$. Arai. We greatly appreciate constructive review of the present article by Kosuke Heki and the Associate Editor, through which the original version has been much improved. We also thank the relevant observatories and institutes in Japan and the International Monitoring System. 


\section{References}

Artru, J., V. Ducic, H. Kanamori, P. Lognonne, and M. Murakami (2005), Ionospheric detection of gravity waves induced by tsunamis, Geophys. J. Int., 160, 840-848, doi:10.1111/j.1365-246X.2005.02552.x.

Banerjee, P., F. Politz, and R. Burgmann (2005), The size and duration of the Sumatra-Andaman earthquake from far-field static offsets, Science, 308, 1769-1772, doi:10.1126/science.1113746.

Banerjee, P., F. Politz, B. Nagarajan, and R. Burgmann (2007), Coseismic slip distributions of the 26 December 2004 Sumatra-Andaman and 28 March 2005 Nias earthquakes from GPS static offsets, Bull. Seismol. Soc. Am., 97, S86-S102, doi:10.1785/0120050609.

Bilham, R., R. Engdahl, N. Feldl, and S. P. Satyabala (2005), Partial and complete rupture of the Indo-Andaman plate boundary, 1847-2004, Seismol. Res. Lett., 76, 299-311.

Bolt, B. A. (1964), Seismic air waves from the great 1964 Alaskan earthquake, Nature, 202, 1095-1096, doi:10.1038/2021095a0.

Chlieh, M., et al. (2007), Coseismic slip and afterslip of the great $M_{w} 9.15$ Sumatra-Andaman earthquake of 2004, Bull. Seismol. Soc. Am., 97, S152-S173, doi:10.1785/0120050631.

DasGupta, A., A. Das, D. Hui, K. K. Bandyopadhyay, and M. R. Sivaraman (2006), Ionospheric perturbations observed by the GPS following the December 26th, 2004 Sumatra-Andaman earthquake, Earth Planets Space, 58, 167-172.

Fujii, Y., and K. Satake (2007), Tsunami source of the 2004 SumatraAndaman earthquake inferred from tide gauge and satellite data, Bull. Seismol. Soc. Am., 97, S192-S207, doi:10.1785/0120050613.

Garces, M., P. Caron, and C. Hetzer (2005), Deep infrasound radiated by the Sumatra earthquake and tsunami, EOS Trans. $A G U, 86(35), 317-$ 319, doi:10.1029/2005EO350002.

Harkrider, D. G. (1964), Theoretical and observed acoustic-gravity waves from explosive sources in the atmosphere, J. Geophys. Res., 69, $5295-$ 5321, doi:10.1029/JZ069i024p05295.

Harkrider, D. G., and F. Press (1967), The Krakatoa air-sea waves: An example of pulse propagation in coupled systems, Geophys. J. R. Astron. Soc., 13, 149-159.

Hashimoto, M., N. Choosakul, M. Hashizume, S. Takemoto, H. Takiguchi, Y. Fukada, and K. Fujimori (2006), Crustal deformation associated with the great Sumatra-Andaman earthquake deduced from continuous GPS observation, Earth Planets Space, 58, 127-139.

Hedin, A. E. (1991), Extension of the MSIS thermosphere model into the middle and lower atmosphere, J. Geophys. Res., 96, 1159-1172, doi:10.1029/90JA02125.

Heki, K., Y. Otsuka, N. Choosakul, N. Hemmakom, T. Komolmis, and T. Maruyama (2006), Detection of ruptures of Andaman fault segments in the 2004 great Sumatra earthquake with coseismic ionospheric disturbances, J. Geophys. Res., 111, B09313, doi:10.1029/2005JB004202.

Iyemori, T., et al. (2005), Geomagnetic pulsations caused by the Sumatra earthquake on December 26, 2004, Geophys. Res. Lett., 32, L20807, doi:10.1029/2005GL024083.

Kajiura, K. (1963), The leading wave of a tsunami, Bull. Earthquake Res. Inst. Univ. Tokyo, 41, 535-571.

Kajiura, K. (1970), Tsunami source, energy and the directivity of wave radiation, Bull. Earthquake Res. Inst. Univ. Tokyo, 48, 835-869.

Lay, T., et al. (2005), The great Sumatra-Andaman earthquake of 26 December 2004, Science, 308, 1127-1133, doi:10.1126/science.1112250.

Le Pichon, A., P. Herry, P. Mialle, J. Vergoz, N. Brachet, M. Garces, D. Drob, and L. Ceranna (2005), Infrasound associated with the 2004-2005 large Sumatra earthquakes and tsunami, Geophys. Res. Lett., 32, L19802, doi:10.1029/2005GL023893.

Liu, J. Y., Y. B. Tsai, S. W. Chen, C. P. Lee, Y. C. Chen, H. Y. Yen, W. Y Chang, and C. Liu (2006), Giant ionospheric disturbances excited by the M9.3 Sumatra earthquake of 26 December 2004, Geophys. Res. Lett., 33, L02103, doi:10.1029/2005GL023963.
Meltzner, A. J., K. Sieh, M. Abrams, D. C. Agnew, K. W. Hudnut, J.-P. Avousac, and D. H. Natawidjaja (2006), Uplift and subsidence associated with the great Aceh-Andaman earthquake of 2004, J. Geophys. Res., 111, B02407, doi:10.1029/2005JB003891.

Mikumo, T. (1968), Atmospheric pressure waves and tectonic deformation associated with the Alaskan earthquake of March 28, 1964, J. Geophys. Res., 73, 2009-2025, doi:10.1029/JB073i006p02009.

Mikumo, T., and B. A. Bolt (1985), Excitation mechanism of atmospheric pressure waves from the 1980 Mount St. Helens eruption, Geophys. J. R. Astron. Soc. 81, 445-461.

Otsuka, Y., N. Kotake, T. Tsugawa, K. Shiokawa, T. Ogawa, E. S. Saito, M. Kawamura, T. Maruyama, N. Hemmakorn, and T. Komolmis (2006), GPS detection of total electron content variations over Indonesia and Thailand following the 26 December 2004 earthquake, Earth Planets Space, 58, 159-165.

Pfeffer, R. L., and J. Zarichny (1963), Acoustic-gravity waves propagation in an atmosphere with two sound channels, Pure Appl. Geophys., 55, 175-199, doi:10.1007/BF02011231.

Press, F., and D. Harkrider (1962), Propagation of acoustic-gravity waves in the atmosphere, J. Geophys. Res., 67, 3889-3908, doi:10.1029/ JZ067i010p03889.

Rajendran, C. P., K. Rajendran, R. Anu, A. Earnest, T. Machado, P. M. Mohan, and J. Freymueller (2007), Crustal deformation and seismic history associated with the 2004 Indian Ocean earthquake: A perspective from the Andaman-Nicobar Islands, Bull. Seismol. Soc. Am., 97, S174S191, doi:10.1785/0120050630.

Shinagawa, H., T. Iyemori, S. Saito, and T. Maruyama (2007), A numerical simulation of ionospheric and atmospheric variations associated with the Sumatra earthquake on December 26, 2004, Earth Planets Space, 59, $1015-1026$

Singh, S. K., M. Ortiz, H. K. Gupta, and G. A. Ramadass (2006), Slow slip below Port Blair, Andaman, during the great Sumatra-Andaman earthquake of 26 December 2004, Geophys. Res. Lett., 33, L03313, doi:10.1029/2005GL025025.

Subarya, C., M. Chlieh, L. Prawirodirdjo, J.-P. Avouac, Y. Bock, K. Sieh, A. J. Meltzner, D. H. Natawidjaja, and R. McCaffrey (2006), Plateboundary deformation associated with the great Sumatra-Andaman earthquake, Nature, 440, 46-51.

Tanioka, Y., T. Yudhicara, T. Kusunose, S. Kathiroli, Y. Ishihara, S. Iwasaki, and K. Satake (2006), Rupture process of the 2004 great SumatraAndaman earthquake estimate from tsunami waveforms, Earth Planets Space, 58, 203-209.

Vigny, C., et al. (2005), Insight into the 2004 Sumatra-Andaman earthquake from GPS measurements in southeast Asia, Nature, 436, 201-206, doi: $10.1038 /$ nature 03937 .

Watada, S., T. Kunugi, K. Hirata, H. Sugioka, K. Nishida, S. Sekiguchi, J. Oikawa, Y. Tsujii, and H. Kanamori (2006), Atmospheric pressure change associated with the 2003 Tokachi-Oki earthquake, Geophys. Res. Lett., 33, L24306, doi:10.1029/2006GL027967.

Yeh, K. C., and C. H. Liu (1974), Acoustic-gravity waves in the upper atmosphere, Rev. Geophys. Space Phys., 12, 193-216, doi:10.1029/ RG012i002p00193.

D. Fee and M. Garces, Infrasound Laboratory, University of Hawaii, 73-4460 Queen Kaahumanu Highway, Suite 119, Kailua-Kona, HI 96740 USA.

A. Le Pichon, DSO, LDG, DASE, CEA, F-91297 Bruyeres-le Chatel, France.

T. Mikumo, W. Morii, and T. Shibutani, Disaster Prevention Research Institute, Kyoto University, Gokasho, Uji, Kyoto 611-0011, Japan. (mikumo@) maia.eonet.ne.jp)

T. Tsuyuki, Matsushiro Seismological Observatory, JMA, Matsushiro, Nagano 382-1232, Japan.

S. Watada, Earthquake Research Institute, University of Tokyo, Yayoi 1-1-1, Bunkyo-ku, Tokyo 113-0032, Japan. 